\title{
Donor-side morbidity after contralateral C-7 nerve transfer: results at a minimum of 6 months after surgery
}

\author{
Xiang-Ming Li, MD, PhD, ${ }^{1,2}$ Jian-Tao Yang, MD, PhD, ${ }^{1}$ Yi Hou, MD, PhD, ${ }^{1}$ Yi Yang, MD, PhD, ${ }^{1}$ \\ Ben-Gang Qin, MD, PhD, ${ }^{1}$ Guo Fu, MD, PhD, ${ }^{1}$ and Li-Qiang Gu, MD, PhD ${ }^{1}$ \\ 1Department of Microsurgery and Orthopedic Trauma, First Affiliated Hospital of Sun Yat-sen University, Guangzhou, \\ Guangdong; and ${ }^{2}$ Department of Orthopedic Surgery, First Affiliated Hospital of Henan University of Science and Technology, \\ Luoyang, Henan, China
}

OBJECTIVE Donor-side morbidity associated with contralateral C-7 (CC7) nerve transfer remains controversial. The purpose of this study was to evaluate functional deficits in the donor limb resulting from prespinal route CC7 nerve transfer.

METHODS A total of 63 patients were included. Forty-one patients had undergone CC7 nerve transfer surgery at least 6 months previously and were assigned to one of 2 groups based on the duration of postoperative follow-up. Group 1 $(n=21)$ consisted of patients who had undergone surgery between 6 months and 2 years previously, and Group 2 ( $n$ = 20) consisted of patients who had undergone surgery more than 2 years previously. An additional 22 patients who underwent CC7 nerve transfer surgery later than those in Groups 1 and 2 were included as a control group (Group 3). Results of preoperative testing in these patients and postoperative testing in Groups 1 and 2 were compared. Testing included subjective assessments and objective examinations. An additional 3 patients had undergone surgery more than 6 months previously but had severe motor weakness and were therefore evaluated separately; these 3 patients were not included in any of the study groups.

RESULTS The revised Short-Form McGill Pain Questionnaire (SF-MPQ-2) was the only subjective test that showed a significant difference between Group 3 and the other 2 groups, while no significant differences were found in objective sensory, motor, or dexterity outcomes. The interval from injury to surgery for patients with a normal SF-MPQ-2 score in Groups 1 and 2 was significantly less than for those with abnormal SF-MFQ-2 scores $(2.4 \pm 1.1$ months vs $4.6 \pm 2.9$ months, $p=0.002$ ). The 3 patients with obvious motor weakness showed a tendency to gradually recover.

CONCLUSIONS Although some patients suffered from long-term sensory disturbances, resection of the C-7 nerve had little effect on the function of the donor limb. Shortening preoperative delay time can improve sensory recovery of the donor limb.

http://thejns.org/doi/abs/10.3171/2015.3.JNS142213

KEY WORDS contralateral C-7 nerve transfer; donor site morbidity; clinical assessment; peripheral nerve

$\mathrm{T}$ REATMENT of total brachial plexus avulsion injury is considered a great challenge due to lack of donor nerves. Currently available extraplexal donors include the spinal accessory nerve, the phrenic nerve, intercostal nerves, and the contralateral C-7 spinal nerve (CC7).$^{19}$ In some severe cases, $\mathrm{CC} 7$ nerve transfer may be the only treatment option.

The surgical procedure involving CC7 nerve transfer was first introduced by Gu et al. in $1986 .{ }^{14}$ It offers a promising approach for treatment of brachial plexus root avulsion injury. Since the introduction of this procedure, many operative methods have been developed, including prespinal route $\mathrm{CC} 7$ nerve transfer, ${ }^{23,35,36}$ hemi-CC7 nerve transfer, ${ }^{29,32}$ and single-stage operation. ${ }^{5,35}$

The C-7 spinal nerve contains over 27,000 myelinated fibers, ${ }^{11}$ an abundance which far outnumbers other nerves used for transfers in brachial plexus reconstruction. Donor site complications associated with CC7 nerve transfer have been reported. ${ }^{4,14,22,25,27,30,31,32,35}$ Some authors ${ }^{4,14,22,27,30,32,38}$ found that patients who underwent CC7 transfer experienced mild and transient donor-side sensory or motor changes, and the motor and sensory functions recovered to

ABBREVIATIONS BMI = body mass index; CC7 = contralateral C-7 spinal nerve; M-ASES = modified American Shoulder and Elbow Surgeons questionnaire; MHQ = Michigan Hand Outcomes Questionnaire; SF-MPQ-2 = Short-Form McGill Pain Questionnaire; SWM = Semmes-Weinstein monofilament; s2PD = static 2-point discrimination. SUBMITTED September 25, 2014. ACCEPTED March 23, 2015.

INCLUDE WHEN CITING Published online September 11, 2015; DOI: 10.3171/2015.3.JNS142213. 
normal levels by approximately 6 months postoperatively. Nevertheless, it has also been reported ${ }^{4,22,30,31}$ that a few patients experienced motor and/or sensory deficits in the donor limbs at 1.5 to 3 years postoperatively.

In 2012, Sammer et al..$^{27}$ reported on 1 patient who sustained permanent motor deficits on the donor side. Donorside morbidity associated with this technique remains controversial, but few comprehensive evaluations of nerve injury from CC7 nerve transfer have been performed that included both subjective and objective examinations. ${ }^{10}$ Therefore, the aim of this study was to evaluate the functional loss in the donor limb caused by resection of the C-7 nerve through both subjective and objective scoring.

\section{Methods}

This study was an assessment of motor and sensory function in the donor-side upper extremity of patients with posttraumatic brachial plexus injuries who had undergone CC7 nerve transfer at least 6 months previously as well as similarly injured patients who had not yet undergone nerve transfer. The study was approved by the institutional review board of the First Affiliated Hospital of Sun Yatsen University.

\section{Participants}

Written informed consent was obtained from all participants prior to their participation in the study.

From May 2008 to December 2013, 123 patients underwent $\mathrm{CC} 7$ nerve transfer via the prespinal route for treatment of posttraumatic brachial plexus injuries at our institution. Eighty-one of these patients were treated between May 2008 and October 2012, and 42 were treated between November 2012 and December 2013. Patients were excluded from the study if they 1) had an associated injury in the contralateral limb, 2) had a combined injury of the spinal cord, 3 ) were less than 18 years old, 4) presented with peripheral neuropathy, or 5) refused to participate. In addition, 3 patients who underwent surgery between May 2008 and October 2012 had obvious motor weakness and were excluded from the group analyses and evaluated separately.

A total of 63 patients ( 60 males and 3 females, average age, 31.8 years) were included in the study. Patients who received CC7 nerve transfer surgery from May 2008 to October 2012 were divided into 2 postoperative evaluation groups (Groups 1 and 2) based on the amount of time that had elapsed since CC7 nerve transfer surgery (duration of follow-up). For patients in Group $1(\mathrm{n}=21)$, the duration of follow-up ranged from 6 months to 2 years, whereas patients in Group $2(n=20)$ all had more than 2 years of follow-up. Since many authors ${ }^{4,14,22,27,30,32,38}$ have reported restoration of normal function in the donor limb within 6 months after CC7 nerve transfer surgery, only patients who had undergone surgery at least 6 months previously were included in the postoperative evaluation groups. Two years after surgery was regarded as the demarcation point between Group 1 and Group 2, because recovery of motor function is scarcely possible after this time point due to muscle fibrosis. ${ }^{14}$

Group $3(n=22)$, the control group, was composed of patients who underwent $\mathrm{CC} 7$ nerve transfer surgery for the treatment of posttraumatic brachial plexus injuries between November 2012 and December 2013. The results of their preoperative assessment were used for the present study. This control group was selected instead of using healthy volunteers because of possible differences between the contralateral limb function of patients with unilateral brachial plexus injury and individuals without such injury. ${ }^{29}$

In addition, 3 patients who had undergone $\mathrm{CC} 7$ nerve transfer surgery and suffered from obvious postoperative motor weakness were evaluated separately, as stated above. These 3 patients were not included in the study groups, because their abnormalities could cause outliers in each of the investigated parameters and thus influence the results of our statistical analysis.

\section{Surgical Technique}

All of the procedures were performed by the senior author (L.Q.G.). The patient was placed in the supine position with a sandbag under the interscapular region. The injured brachial plexus was explored through a supraclavicular transverse incision to confirm root avulsion. On the contralateral side, a similar incision was made. The contralateral C-7 nerve was identified by surgical exploration and electrical stimulation, and transected at the distal end of the divisions. Before dividing the C-7 nerve, a small amount of $2 \%$ lidocaine was injected via the epineurial route to protect the proximal neurons. After making a tunnel posterior to the scalenus anterior muscle, a retroesophageal space was created by blunt dissection. Then, the contralateral C-7 nerve was passed to the injured side and coapted to the recipient nerve by means of direct neurorrhaphy or nerve grafting. The patient was required to wear a head-shoulder spica cast for 6 weeks after the operation to prevent rupture of the nerve suture. No special treatment was given to the donor limb after surgery.

\section{Testing Protocol}

Once the patient was deemed appropriate for inclusion in the study, 3 types of subjective assessments, 3 objective sensory examinations, and quantitative muscle strength and dexterity testing were performed to evaluate the functional loss in the donor limb. All tests were performed by 2 trained physicians. One physician was responsible for subjective assessments, and the other for objective examinations.

\section{Subjective Assessment}

The revised Short-Form McGill Pain Questionnaire (SF-MPQ-2) was used to assess the qualities of pain.., 24 Each descriptor had a $0-10$ numerical rating scale $(0=$ "no pain"; 10 = "pain as bad as you can imagine"). Predominantly neuropathic pain descriptors (6 items) included "hot-burning pain," "cold-freezing pain," "pain caused by light touch," "itching," "tingling," and "numbness." Good validity and reliability have been shown for the SFMPQ-2. ${ }^{9}$ Two other subjective assessments included the Michigan Hand Outcomes Questionnaire (MHQ), and modified American Shoulder and Elbow Surgeons ques- 
tionnaire (M-ASES). The MHQ was designed as a general survey of hand function and includes 25 items for the right and the left hand, as well as questions pertaining to both hands. ${ }^{6}$ The M-ASES is considered an excellent tool for measuring whole upper-extremity dysfunction. ${ }^{8}$

\section{Sensory Assessment}

Objective sensory assessments included object recognition, Semmes-Weinstein monofilament (SWM) examination, and static 2-point discrimination (s2PD). Six common objects (a key, a paper clip, a teaspoon, a short pencil, a button, and a coin) were chosen for the object recognition test. ${ }^{17}$ One point was awarded for any object recognized correctly. According to the method described by Rosen et al., ${ }^{26}$ the sum of SWM and s2PD scores from 6 critical sites on the donor-side hand (Fig. 1) were recorded.

\section{Motor Assessment}

Quantitative testing of muscle strength was performed using an isometric dynamometer (microFET2, Hoggan Health Industries Inc.). Motor evaluation focused on the muscles associated with C-7 innervation including the triceps, extensor digitorum communis, flexor carpi radialis, flexor carpi ulnaris, extensor carpi radialis, and extensor carpi ulnaris ${ }^{20}$ The biceps was used as a reference for motor assessment. We did not measure the strength of other muscles such as the latissimus dorsi due to the significant effect of synergistic muscles. Subject position, placement of the dynamometer, and location of stabilization were carried out, as described by Kendall and Kendall. ${ }^{16}$ Three

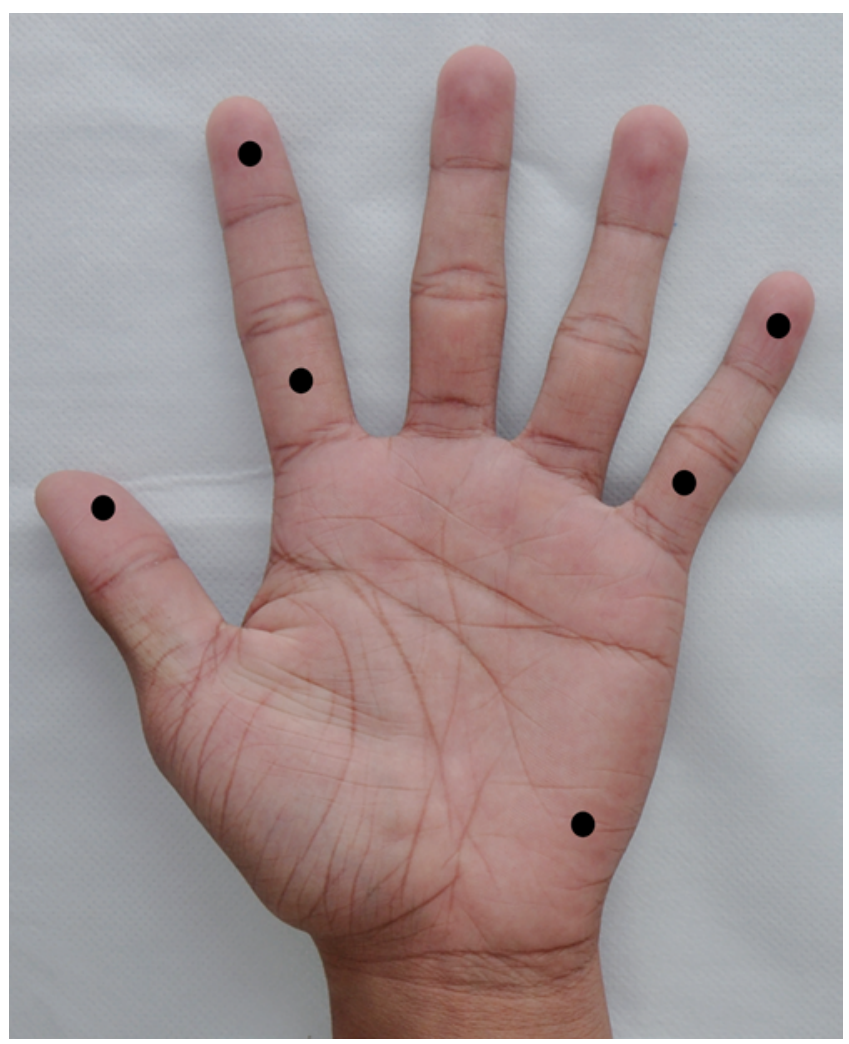

FIG. 1. Photograph showing the 6 critical assessment sites on the donor-side hand. Figure is available in color online only. trials were performed for each muscle, with rest periods of 15 seconds between trials, and a mean value was recorded.

Grip strength was measured using a Jamar dynamometer (Sammons Preston) and pinch strength using a pinch gauge (Sammons Preston). The Purdue Pegboard Test (Model 32020, Lafayette Instrument Company) was used as a test of fine dexterity. ${ }^{37}$ These tests were also repeated 3 times to obtain an average for each patient.

\section{Statistical Analysis}

The 3 groups were independent (no patient was included in more than 1 group). The significance level (i.e., alpha) of 0.05 was applied to each test in this study. Since there were 3 consistent groups for every variable, a 1-way ANOVA was used to test differences for continuous variables and a chi-square test for categorical variables. The mean and standard deviation were reported for continuous variables; counts and proportion (\%) were reported for categorical variables.

In addition to the above analysis, all patients in Groups 1 and 2 were reassigned to either a normal (SF-MPQ-2 = 0 ) or an abnormal (SF-MPQ-2 > 0) group using the SFMPQ-2 criteria. Variables were compared by independent-samples t-test and chi-square test.

\section{Results}

\section{Patient Characteristics}

The characteristics of the patients in the 3 groups are shown in Table 1 . The mean follow-up time was $10.2 \pm 3.8$ months for Group 1 versus $37.2 \pm 9.7$ months for Group 2 $(\mathrm{p}<0.001)$. No significant differences were found between the 3 groups regarding the other variables, including age, sex, and body mass index (BMI).

\section{Subjective Assessment}

Of the 3 types of subjective assessments used in this study, only the SF-MPQ-2 showed significant differences between groups $(\mathrm{p}<0.001$, Table 2$)$. The average SFMPQ-2 scores for Groups 1, 2, and 3 were $2.6 \pm 2.5,1.9 \pm$ 2.6 , and 0, respectively. Further post hoc analysis (Dunn's test) showed that the mean SF-MPQ-2 score for Group 3 was significantly lower compared than the mean scores for Groups 1 and 2 ( $p<0.001$ and $p=0.008$, respectively).

In the SF-MPQ-2 assessment, neuropathic pain symptoms were most commonly reported in the index finger, middle finger, and thumb; they were occasionally reported in the ring finger and along the radial side of the dorsal hand. Sensory changes gradually became limited to the distal pulp of the index finger as recovery time increased.

Fifteen $(71 \%)$ of the 21 patients in Group 1 and 10 (50\%) of the 20 patients in Group 2 had abnormal SFMPQ-2 scores. Items involved in the scoring included "numbness," "tingling," and "pain caused by light touch." Any given patient could report 1 or more symptoms. The percentage of patients from Group 1 who reported "numbness" in their fingers was slightly higher (43\%) than in Group $2(30 \%)$. Fewer patients in either Group 1 or Group 2 complained of "tingling" or "pain caused by light touch" in their fingers.

Based on their SF-MPQ-2 scores, patients in Groups 1 
TABLE 1. Comparison of the demographic and clinical characteristics of the 63 patients in the 3 study groups*

\begin{tabular}{|c|c|c|c|c|}
\hline Characteristic & Group $1(n=21)$ & Group $2(n=20)$ & Group $3(n=22)$ & p Value $†$ \\
\hline Age in yrs & & & & 0.970 \\
\hline Mean (SD) & $32.0(9.9)$ & $32.1(10.1)$ & $31.3(11.8)$ & \\
\hline Range & $18-55$ & $19-59$ & $18-60$ & \\
\hline $\mathrm{BMI}$ in $\mathrm{kg} / \mathrm{m}^{2}$ & & & & 0.084 \\
\hline Mean (SD) & $23.6(3.3)$ & $22.1(3.6)$ & $21.3(2.8)$ & \\
\hline Range & $16.9-30.5$ & $15.6-27.7$ & $17.6-27.4$ & \\
\hline Interval from injury to op in mos & & & & 0.960 \\
\hline Mean (SD) & $3.7(2.5)$ & $3.9(2.8)$ & $3.9(2.2)$ & \\
\hline Range & $1-9$ & $1-11$ & $1-10$ & \\
\hline Follow-up time in mos & & & & $<0.001 \ddagger$ \\
\hline Mean (SD) & $10.2(3.8)$ & $37.2(9.7)$ & NA & \\
\hline Range & $6-18$ & $24-53$ & NA & \\
\hline Sex & & & & 0.358 \\
\hline Male & $19(90 \%)$ & $20(100 \%)$ & $21(95 \%)$ & \\
\hline Female & $2(10 \%)$ & 0 & $1(5 \%)$ & \\
\hline Investigated side & & & & 0.124 \\
\hline Right & $14(67 \%)$ & $16(80 \%)$ & $11(50 \%)$ & \\
\hline Left & $7(33 \%)$ & $4(20 \%)$ & $11(50 \%)$ & \\
\hline Patterns of injury & & & & 0.517 \\
\hline Upper trunk & $3(14 \%)$ & $1(5 \%)$ & $3(14 \%)$ & \\
\hline Upper \& middle trunk & $1(5 \%)$ & $4(20 \%)$ & $4(18 \%)$ & \\
\hline Pan-plexus & $17(81 \%)$ & $15(75 \%)$ & $15(68 \%)$ & \\
\hline $\begin{array}{l}\mathrm{VA}=\text { not applicable. } \\
\text { Values are numbers of patients (\%) } \\
\text { Based on 1-way ANOVA and chi-sq } \\
\text { An independent-samples t-test was }\end{array}$ & $\begin{array}{l}\text { therwise indicated. } \\
\text { ts unless otherwise } \\
\text { to assess follow-up }\end{array}$ & $\begin{array}{l}\text { d. } \\
\text { Groups } 1 \text { and } 2 .\end{array}$ & & \\
\hline
\end{tabular}

and 2 were reassigned into normal and abnormal groups, and variables were compared (Table 3 ). The interval from injury to surgery for the group with normal results on the SF-MPQ-2 (2.4 \pm 1.1 months) was significantly less than the interval for the group with abnormal results $(4.6 \pm 2.9$ months, $\mathrm{p}=0.002)$. No significant differences were found regarding the other variables.

\section{Sensory Assessment}

As can be seen in Table 4, the object recognition scores were identical for all 3 groups. In addition, there were no significant differences in SWM and s2PD scores.

\section{Motor Assessment}

Quantitative muscle strength testing of specific muscles revealed no significant differences among the 3 groups (Table 4). In grip and pinch strength tests, tip pinch strength was the only test that showed a significant difference $(\mathrm{p}=$ 0.004, Table 4). The mean scores for tip pinch strength in Groups 1, 2, and 3 were $12.01 \pm 2.78 \mathrm{lbs}, 14.97 \pm 2.87$ $\mathrm{lbs}$, and $13.77 \pm 2.64 \mathrm{lbs}$, respectively. Post hoc analysis (t-test with Bonferroni correction), showed no significant differences between Group 3 and the other 2 groups ( $p=$ 0.122 and $p=0.497$, respectively), while the mean score for Group 2 was significantly higher than that of Group 1 $(p=0.003)$. The average scores from the Purdue Pegboard
Test were $14.79 \pm 2.53,15.32 \pm 1.69$, and $15.39 \pm 1.75$ for Groups 1, 2, and 3, respectively $(\mathrm{p}=0.587)$.

\section{Evaluation of 3 Patients With Obvious Motor Weakness}

Of the 123 patients, 3 patients suffered from obvious motor weakness. Postoperative motor weakness manifested as significant decreases in the extensor digitorum communis and triceps muscle strength (M2, as measured on the Medical Research Council's ascending scale of muscle strength: Grades M0-M5), although there was a trend of continuous improvement in motor function with increased length of follow-up.

The first of these 3 patients (Case 1) was followed up for 10 months. The strength in the extensor digitorum communis and triceps was M3 and M4, respectively. The second patient (Case 2) was followed up for 15 months. The strength in the extensor digitorum communis and triceps was M3 and M4, respectively. The third patient (Case 3) was followed up for 25 months. At the 9-month follow-up evaluation, the strength in his extensor digitorum communis and triceps was M2 and M4, respectively. At 25 months after surgery, no motor or sensory dysfunction was noted in the healthy limb. The strength in the extensor digitorum communis and triceps was M4, and he was able to lift a 7.5-kg dumbbell with the donor limb (Fig. 2). During the early postoperative period, the patient's subjective assessment regarding his healthy limb function was "ex- 
TABLE 2. Results of subjective assessments*

\begin{tabular}{llcll}
\hline Variable & $\begin{array}{c}\text { Group 1 } \\
(\mathrm{n}=21)\end{array}$ & $\begin{array}{c}\text { Group 2 } \\
(\mathrm{n}=20)\end{array}$ & $\begin{array}{c}\text { Group 3 } \\
(\mathrm{n}=22)\end{array}$ & $\mathrm{p} \mathrm{Value}$ \\
\hline $\mathrm{MHQ}$ & & & & 0.384 \\
\hline Mean (SD) & $70.6(10.2)$ & $74.1(7.5)$ & $73.8(9.1)$ & \\
\hline Range & $50.1-83.3$ & $53.5-83.3$ & $49.7-83.3$ & \\
\hline M-ASES & & & & 0.261 \\
\hline Mean (SD) & $31.8(5.5)$ & $34.2(4.6)$ & $33.7(4.4)$ & \\
\hline Range & $24-39$ & $26-39$ & $23-39$ & \\
\hline SF-MPQ-2 & & & & $<0.001 \dagger$ \\
\hline Mean (SD) & $2.6(2.5)$ & $1.9(2.6)$ & 0 & \\
\hline Range & $0-9$ & $0-9$ & 0 & \\
\hline Normal & $6(29 \%)$ & $10(50 \%)$ & $22(100 \%)$ & \\
\hline Numbness & $9(43 \%)$ & $6(30 \%)$ & 0 & \\
\hline Tingling & $4(19 \%)$ & $2(10 \%)$ & 0 & \\
\hline Pain caused by & $4(19 \%)$ & $4(20 \%)$ & 0 & \\
$\quad$ light touch & & & & \\
\hline
\end{tabular}

* Values are numbers of patients (\%) unless otherwise indicated.

$\dagger$ Kruskal-Wallis 1-way ANOVA was utilized to evaluate SF-MPQ-2, as no variance existed in Group 3.

tremely dissatisfied," but this assessment improved to "basically satisfied" by 25 months after the operation.

\section{Discussion}

Donor-site morbidity of $\mathrm{CC} 7$ nerve transfer remains controversial as surgeons are concerned with the possibility of creating a new deficit with sacrifice of the donor nerve. We assessed the functional loss in the donor limb using both subjective assessments and objective examinations. The SF-MPQ-2 test was the only subjective test that showed a significant difference between Group 3 and all other groups, while no significant differences were found in objective sensory, motor, or dexterity outcomes between Group 3 and the other groups.

Regarding the SF-MPQ-2 assessment, many patients still complained of sensory abnormalities 6 months postoperatively, which differed from the results of other studies. ${ }^{4,14,27,30,31,32,35}$ One of the possible reasons for this discrepancy was a difference in technique between studies; some authors performed hemi-CC7 nerve transfer to reduce donor-side morbidity. ${ }^{27,30,32}$ Another reason may be related to the use of a verbal patient response to assess symptoms of the donor limb, which may have underestimated the extent of nerve damage. Collins et al. ${ }^{7}$ evaluated patients after upper-extremity nerve injury, with $76 \%$ reporting cold intolerance, and most of these patients continued to have symptoms 5 years after injury.

In the present study, the mean interval from injury to surgery for the patients with normal SF-MPQ-2 scores in Groups 1 and 2 was significantly less than the corresponding interval in patients with abnormal scores $(2.4 \pm$ 1.1 months vs $4.6 \pm 2.9$ months, $\mathrm{p}=0.002$ ). This finding suggested that the shorter the preoperative delay time, the better the recovery of sensory function in the donor limb, similar to the findings of Ali et al. ${ }^{1}$ The reason for this improved recovery may be related to cross-transfer effects.
TABLE 3. Comparison of demographic and clinical characteristics in the postoperative patients (Groups 1 and 2) stratified by SF-MPQ-2 results*

\begin{tabular}{|c|c|c|c|}
\hline Variable & $\begin{array}{l}\text { Normal } \\
(n=16)\end{array}$ & $\begin{array}{c}\text { Abnormal } \\
(n=25)\end{array}$ & $\begin{array}{c}p \\
\text { Value }\end{array}$ \\
\hline Interval from injury to op in mos & & & 0.002 \\
\hline Mean (SD) & $2.4(1.1)$ & $4.6(2.9)$ & \\
\hline Range & $1-5$ & $1-11$ & \\
\hline Age in yrs & & & 0.717 \\
\hline Mean (SD) & $31.3(10.4)$ & $32.5(9.7)$ & \\
\hline Range & $18-55$ & $19-19$ & \\
\hline $\mathrm{BMI}$ in $\mathrm{kg} / \mathrm{m}^{2}$ & & & 0.051 \\
\hline Mean (SD) & $21.5(3.6)$ & $23.7(3.3)$ & \\
\hline Range & $17.0-30.5$ & $15.6-29.8$ & \\
\hline Sex & & & 0.744 \\
\hline Male & 15 & 24 & \\
\hline Female & 1 & 1 & \\
\hline Investigated side & & & 0.350 \\
\hline Right & 13 & 17 & \\
\hline Left & 3 & 8 & \\
\hline Patterns of injury & & & 0.492 \\
\hline Upper trunk & 2 & 2 & \\
\hline Upper \& middle trunk & 3 & 2 & \\
\hline Pan-plexus & 11 & 21 & \\
\hline
\end{tabular}

Previous studies have shown that unilateral peripheral nerve lesions can affect contralateral nonlesioned neurons, and the magnitude of abnormalities due to cross-transfer effects follows a specific time sequence..$^{15,28,29}$ Therefore, earlier repair of nerve lesions in the injured limb could reduce the deleterious effects on the nerve of the donor limb. However, our observations implied that sensory function was more susceptible to influence than motor function in this study. One explanation is that synergistic muscle activity from distant sites may compensate for deficits in motor function, while the sensory function does not have such a compensatory mechanism.

In the present study, objective sensory tests (such as the SWM examination) showed no significant differences among the 3 groups; this was inconsistent with results from the SF-MPQ-2. This finding may be related to the limitations of the sensory tests. The monofilament examination only evaluated the function of large myelinated nerve fibers, ${ }^{34}$ whereas the S2PD was not sensitive in detecting mild sensory loss..$^{25}$ In this study, however, the abnormal SF-MPQ-2 scores were relatively low, and the MHG and M-ASES scores also failed to show significance, indicating that the residual sensory abnormalities had little significant effect on donor limb function.

Transecting the nerve root affords the opportunity to study the C-7 dermatome. After the C-7 nerve transection, patients experienced "numbness," "tingling," and other symptoms in the fingers of the donor limb. With prolonged recovery time, sensory changes were gradually limited to the distal pulp of the index finger. $\mathrm{Gu}^{12}$ found that the area 
TABLE 4. Results of objective assessments

\begin{tabular}{|c|c|c|c|c|}
\hline Variable & Group $1(n=21)$ & Group $2(n=20)$ & Group $3(n=22)$ & p Value \\
\hline \multicolumn{5}{|l|}{ Sensory assessments } \\
\hline SWM & & & & 0.086 \\
\hline Mean (SD) & $27.9(2.0)$ & $27.0(2.4)$ & $28.4(1.5)$ & \\
\hline Range & $24-30$ & $24-30$ & $25-30$ & \\
\hline s2PD & & & & 0.312 \\
\hline Mean (SD) & $15.0(1.7)$ & $14.9(1.1)$ & $15.6(1.9)$ & \\
\hline Range & $12-18$ & $13-17$ & $11-18$ & \\
\hline Object recognition, mean† & 6 & 6 & 6 & NA \\
\hline \multicolumn{5}{|l|}{ Muscle strength in lbs, mean (SD) } \\
\hline Biceps & $45.40(10.70)$ & $47.76(6.87)$ & $48.43(7.21)$ & 0.476 \\
\hline Triceps & $23.54(5.43)$ & $24.79(6.55)$ & $24.40(4.81)$ & 0.767 \\
\hline ECR & $26.81(3.86)$ & $27.62(4.03)$ & $29.62(4.64)$ & 0.087 \\
\hline ECU & $22.13(4.59)$ & $21.84(4.06)$ & $23.65(3.36)$ & 0.293 \\
\hline FCR & $24.70(4.15)$ & $25.74(4.14)$ & $27.15(4.52)$ & 0.178 \\
\hline FCU & $23.42(5.17)$ & $24.91(3.36)$ & $26.37(4.32)$ & 0.095 \\
\hline EDC & $15.70(3.25)$ & $16.56(3.29)$ & $17.13(4.00)$ & 0.415 \\
\hline \multicolumn{5}{|l|}{ Grip strength in Ibs, mean (SD) } \\
\hline Grip & $81.24(21.49)$ & $92.64(19.09)$ & $87.57(21.18)$ & 0.216 \\
\hline Tip pinch & $12.01(2.78)$ & $14.97(2.87)$ & $13.77(2.64)$ & 0.004 \\
\hline Tri-pinch & $16.68(3.84)$ & $19.38(4.37)$ & $18.42(4.01)$ & 0.107 \\
\hline Key pinch & $19.63(4.46)$ & $22.22(3.54)$ & $20.79(3.24)$ & 0.099 \\
\hline Purdue Pegboard Test, mean (SD) & $14.79(2.53)$ & $15.32(1.69)$ & $15.39(1.75)$ & 0.587 \\
\hline
\end{tabular}

of skin innervated by C-7 was centered on the index finger together with the thumb and middle fingers. Therefore, the key dermatome of C-7 should be the distal pulp of the index finger, rather than the proximal dorsal skin of the middle finger. ${ }^{18}$

In the quantitative motor assessments, there were no significant differences between Group 3 and the other 2 groups, suggesting that the motor function and dexterity of the donor limb can recover to normal levels after CC7 nerve transfer. This finding was similar to results obtained by Chuang and colleagues. ${ }^{4,5}$ In the tip pinch test, patients in Group 2 showed significantly more strength than those in Group 1, which was related to greater use of the hand on the donor side in patients with brachial plexus injury.

Although most patients obtained an excellent functional recovery in the donor limb after resection of the C-7 nerve, the motor weakness that occurred in a few patients still represents a controversial issue. In this study, 3 patients experienced obvious motor weakness, mainly related to the dysfunction of finger and elbow extension. According to the literature, other muscles could also be involved, including the flexor digitorum muscles, intrinsic hand muscles, and thenar eminence..$^{27}$ Wang et al. ${ }^{35}$ felt that loss of function of the extensor digitorum communis was caused by iatrogenic injury to the posterior division of the lower trunk during the process of dissecting the posterior division of the contralateral C-7 nerve. Another reason may be secondary to the "prefixed" brachial plexus anatomical variation, because the lower trunk contributes significantly to innervation of those muscles associated with motor weakness. 2,18,21,39

We also observed, however, that patients with motor weakness obtained satisfactory functional recovery with increased follow-up time, which was consistent with the findings of other researchers., ${ }^{4,30,35}$ Functional deficits caused by nerve injuries can be compensated for by 3 neural mechanisms: reinnervation of denervated targets by regeneration of injured axons, reinnervation by collateral branching of undamaged axons, and remodeling of nervous system circuitry related to the lost function. Thus, some authors have suggested that a long follow-up period is necessary to determine whether adequate function has been recovered. ${ }^{13,33}$ In the study by Sammer et al., ${ }^{27}$ it was not appropriate to report that the patient sustained "permanent" motor deficits on the donor side on the basis of follow-up evaluation performed 10 months postoperatively.

For patients with severe total brachial plexus avulsion injuries, especially patients with a combination injury involving other donor nerves, CC7 nerve transfer may be the only choice to treat nerve injuries. For patients with upper and middle trunk avulsion, various intraplexus and extraplexus nerve transfers have been used. However, a single 


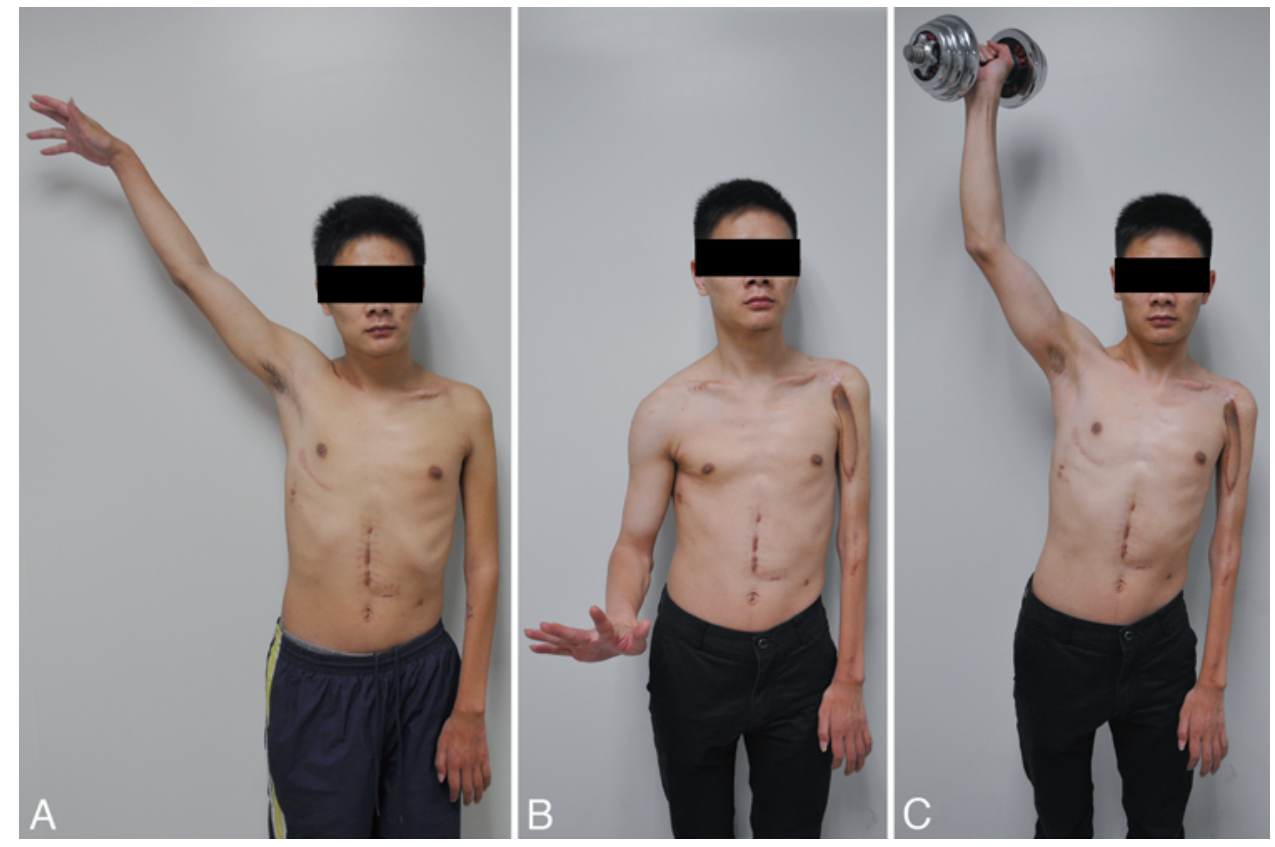

FIG. 2. Case 3. This patient suffered from motor weakness in the donor limb after contralateral C-7 nerve transfer. At the 9-month follow-up visit (A), the strength in the extensor digitorum muscle and triceps was M2 and M4, respectively. At 25 months after surgery (B and $\mathbf{C}$ ), the strength in the extensor digitorum muscle and triceps was $\mathrm{M} 4$, and the patient could lift a 7.5-kg dumbbell with the donor limb. Figure is available in color online only.

C-7 nerve carries vast nerve fibers that exceed the total number present in the frequently used donor nerves such as accessory, phrenic, and intercostal nerves. Therefore, it is reasonable to use C-7 to neurotize more than 1 recipient nerve. ${ }^{3}$ Based on this consideration, we performed CC7 surgery in a small number of patients with upper and middle trunk avulsion, hoping to get the results from multiple nerve transfers through a single CC7 surgery. Zhang and $\mathrm{Gu}$ felt that the double contralateral C-7 nerve transfer should only be used with caution in highly selected cases and that the 2 recipient nerves should innervate muscles with synergistic rather than antagonistic functions. ${ }^{38}$

Our study had several limitations. First, the study design of the study made it potentially subject to systematic error and bias. However, no statistically significant difference was found between the 3 groups with respect to characteristics such as age, sex, and BMI, supporting the comparability of the 3 groups of patients. Second, only about one-half of the patients who underwent CC7 transfer at our institution were evaluated because of the long time required for recovery after brachial plexus injury and reconstruction. In addition, we used a handheld dynamometer to grade motor function in this study. Although handheld dynamometers are used more often in clinical practice, isokinetic dynamometers afford a more precise method of grading motor function.

\section{Conclusions}

Although some patients suffered from mild long-term sensory disturbances, resection of the C-7 nerve had little effect on donor limb function. Shortening preoperative delay time can improve sensory recovery of the donor limb.

\section{Acknowledgments}

The authors acknowledge the financial support from the National Natural Science Foundation (No. 30973059), the Science and Technology Planning Project of Guangdong Province (No. 2013 B021800296), and the National Key Clinical Specialist Construction Programs of China.

\section{References}

1. Ali Z, Meyer RA, Belzberg AJ: Neuropathic pain after C7 spinal nerve transection in man. Pain 96:41-47, 2002

2. Bertelli JA, Ghizoni MF: C5-8 brachial plexus root injury: the "T-1 hand". J Neurosurg 116:409-413, 2012

3. Chen L, Gu YD, Hu SN, Xu JG, Xu L, Fu Y: Contralateral C7 transfer for the treatment of brachial plexus root avulsions in children - a report of 12 cases. J Hand Surg Am 32:96-103, 2007

4. Chuang DC, Cheng SL, Wei FC, Wu CL, Ho YS: Clinical evaluation of $\mathrm{C} 7$ spinal nerve transection: 21 patients with at least 2 years' follow-up. Br J Plast Surg 51:285-290, 1998

5. Chuang DC, Hernon C: Minimum 4-year follow-up on contralateral C7 nerve transfers for brachial plexus injuries. J Hand Surg Am 37:270-276, 2012

6. Chung KC, Pillsbury MS, Walters MR, Hayward RA: Reliability and validity testing of the Michigan Hand Outcomes Questionnaire. J Hand Surg Am 23:575-587, 1998

7. Collins ED, Novak CB, Mackinnon SE, Weisenborn SA: Long-term follow-up evaluation of cold sensitivity following nerve injury. J Hand Surg Am 21:1078-1085, 1996

8. Cook C, Hegedus E, Goode A, Mina C, Pietrobon R, Higgins LD: Relative validity of the modified American Shoulder and Elbow Surgeons (M-ASES) questionnaire using item response theory. Rheumatol Int 28:217-223, 2008

9. Dworkin RH, Turk DC, Revicki DA, Harding G, Coyne KS, Peirce-Sandner S, et al: Development and initial validation of an expanded and revised version of the Short-form McGill Pain Questionnaire (SF-MPQ-2). Pain 144:35-42, 2009 
10. Galanakos SP, Zoubos AB, Johnson EO, Kanellopoulos AD, Soucacos PN: Outcome models in peripheral nerve repair: time for a reappraisal or for a novel? Microsurgery 32:326333, 2012

11. Gu YD: Contralateral C7 root transfer over the last 20 years in China. Chin Med J (Engl) 120:1123-1126, 2007

12. Gu YD: Distribution of the sensory endings of the $\mathrm{C} 7$ nerve root and its clinic significance. J Hand Surg Br 19:67-68, 1994

13. Gu YD, Chen DS, Zhang GM, Cheng XM, Xu JG, Zhang LY, et al: Long-term functional results of contralateral C7 transfer. J Reconstr Microsurg 14:57-59, 1998

14. Gu YD, Zhang GM, Chen DS, Yan JG, Cheng XM, Chen L: Seventh cervical nerve root transfer from the contralateral healthy side for treatment of brachial plexus root avulsion. J Hand Surg Br 17:518-521, 1992

15. Kelly S, Dunham JP, Donaldson LF: Sensory nerves have altered function contralateral to a monoarthritis and may contribute to the symmetrical spread of inflammation. Eur $\mathbf{J}$ Neurosci 26:935-942, 2007

16. Kendall FP, Kendall McCreary E, Provance PG: Muscles Testing and Function, ed 4. Baltimore: Williams and Wilkins, 1993, pp 179-190

17. Kirjavainen M, Remes V, Peltonen J, Rautakorpi S, Helenius I, Nietosvaara Y: The function of the hand after operations for obstetric injuries to the brachial plexus. J Bone Joint Surg Br 90:349-355, 2008

18. Kirshblum SC, Waring W, Biering-Sorensen F, Burns SP, Johansen M, Schmidt-Read M, et al: Reference for the 2011 revision of the International Standards for Neurological Classification of Spinal Cord Injury. J Spinal Cord Med 34:547554,2011

19. Lee SK, Wolfe SW: Nerve transfers for the upper extremity: new horizons in nerve reconstruction. J Am Acad Orthop Surg 20:506-517, 2012

20. Li R, Machol JA IV, Liu X, Hettinger PC, Flugstad NA, Yan JG, et al: C7 nerve root sensory distribution in peripheral nerves: a bold functional magnetic resonance imaging investigation at 9.4 T. Muscle Nerve 49:40-46, 2014

21. Li WJ, Wang SF, Li PC, Li YC, Jin YD, Yang Y, et al: Electrophysiological study of the dominant motor innervation to the extensor digitorum communis muscle and long head of triceps brachii at posterior divisions of brachial plexus. Microsurgery 31:535-538, 2011

22. Liu J, Pho RW, Kour AK, Zhang AH, Ong BK: Neurologic deficit and recovery in the donor limb following cross-C7 transfer in brachial-plexus injury. J Reconstr Microsurg 13:237-243, 1997

23. Mcguiness CN, Kay SP: The prespinal route in contralateral C7 nerve root transfer for brachial plexus avulsion injuries. J Hand Surg Br 27:159-160, 2002

24. Novak CB, Anastakis DJ, Beaton DE, Mackinnon SE, Katz $\mathrm{J}$ : Biomedical and psychosocial factors associated with disability after peripheral nerve injury. J Bone Joint Surg Am 93:929-936, 2011

25. Patel MR, Bassini L: A comparison of five tests for determining hand sensibility. J Reconstr Microsurg 15:523-526, 1999

26. Rosén B, Lundborg G: A model instrument for the documentation of outcome after nerve repair. J Hand Surg Am 25:535-543, 2000

27. Sammer DM, Kircher MF, Bishop AT, Spinner RJ, Shin AY: Hemi-contralateral C7 transfer in traumatic brachial plexus injuries: outcomes and complications. J Bone Joint Surg Am 94:131-137, 2012

28. Shenker N, Haigh R, Roberts E, Mapp P, Harris N, Blake D: A review of contralateral responses to a unilateral inflammatory lesion. Rheumatology (Oxford) 42:1279-1286, 2003

29. Song Y, Forsgren S, Yu J, Lorentzon R, Stål PS: Effects on contralateral muscles after unilateral electrical muscle stimulation and exercise. PLoS One 7:e52230, 2012

30. Songcharoen P, Wongtrakul S, Mahaisavariya B, Spinner RJ: Hemi-contralateral C7 transfer to median nerve in the treatment of root avulsion brachial plexus injury. J Hand Surg Am 26:1058-1064, 2001

31. Sungpet A, Suphachatwong C, Kawinwonggowit V: Sensory abnormalities after the seventh cervical nerve root transfer. Microsurgery 19:287-288, 1999

32. Terzis JK, Kokkalis ZT: Selective contralateral C7 transfer in posttraumatic brachial plexus injuries: a report of 56 cases. Plast Reconstr Surg 123:927-938, 2009

33. Waikakul S, Orapin S, Vanadurongwan V: Clinical results of contralateral C7 root neurotization to the median nerve in brachial plexus injuries with total root avulsions. J Hand Surg Br 24:556-560, 1999

34. Walk D, Sehgal N, Moeller-Bertram T, Edwards RR, Wasan A, Wallace M, et al: Quantitative sensory testing and mapping: a review of nonautomated quantitative methods for examination of the patient with neuropathic pain. Clin J Pain 25:632-640, 2009

35. Wang SF, Li PC, Xue YH, Yiu HW, Li YC, Wang HH: Contralateral $\mathrm{C} 7$ nerve transfer with direct coaptation to restore lower trunk function after traumatic brachial plexus avulsion. J Bone Joint Surg Am 95: 821-827, S1-S2, 2013

36. Xu L, Gu Y, Xu J, Lin S, Chen L, Lu J: Contralateral C7 transfer via the prespinal and retropharyngeal route to repair brachial plexus root avulsion: a preliminary report. Neurosurgery 63:553-559, 2008

37. Yancosek KE, Howell D: A narrative review of dexterity assessments. J Hand Ther 22:258-270, 2009

38. Zhang CG, Gu YD: Contralateral C7 nerve transfer - our experiences over past 25 years. J Brachial Plex Peripher Nerve Inj 6:10, 2011

39. Zhang L, Zhang CG, Dong Z, Gu YD: Spinal nerve origins of the muscular branches of the radial nerve: an electrophysiological study. Neurosurgery 70:1438-1441, 2012

\section{Disclosure}

The authors report no conflict of interest concerning the materials or methods used in this study or the findings specified in this paper.

\section{Author Contributions}

Conception and design: Gu, Li. Acquisition of data: Hou, Y Yang, Qin, Fu. Analysis and interpretation of data: JT Yang. Drafting the article: Li.

\section{Correspondence}

Li-Qiang Gu, Department of Microsurgery and Orthopedic Trauma, the First Affiliated Hospital of Sun Yat-sen University, No. 58 Zhongshan Rd. 2, Guangzhou 510080, China. email: guliqiang 1963@aliyun.com. 